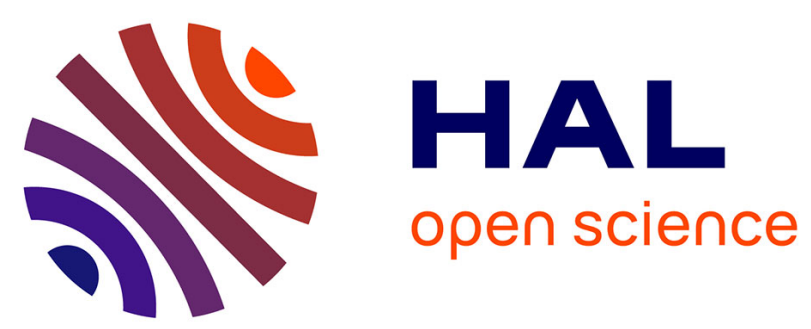

\title{
Major depressive disorder, personality disorders and coping strategies are independent risk factors for lower quality of life in non-metastatic breast cancer patients.
}

Paul Brunault, Anne-Laure Champagne, Grégoire Huguet, Isabelle Suzanne, Jean-Louis Senon, Gilles Body, Emmanuel Rusch, Guillaume Magnin, Mélanie Voyer, Christian Réveillère, et al.

\section{To cite this version:}

Paul Brunault, Anne-Laure Champagne, Grégoire Huguet, Isabelle Suzanne, Jean-Louis Senon, et al.. Major depressive disorder, personality disorders and coping strategies are independent risk factors for lower quality of life in non-metastatic breast cancer patients. . Psycho-Oncology, 2015, 25 (5), pp.513-520 10.1002/pon.3947 . hal-01379522

\author{
HAL Id: hal-01379522 \\ https://hal.science/hal-01379522
}

Submitted on 11 Oct 2016

HAL is a multi-disciplinary open access archive for the deposit and dissemination of scientific research documents, whether they are published or not. The documents may come from teaching and research institutions in France or abroad, or from public or private research centers.
L'archive ouverte pluridisciplinaire HAL, est destinée au dépôt et à la diffusion de documents scientifiques de niveau recherche, publiés ou non, émanant des établissements d'enseignement et de recherche français ou étrangers, des laboratoires publics ou privés. 
Title: Major depressive disorder, personality disorders and coping strategies are independent risk factors for lower quality of life in non-metastatic breast cancer patients.

Short title: Psychological risk factors for lower quality of life after breast cancer.

Authors names and affiliations: Paul Brunault ${ }^{1,2,3}$, Anne-Laure Champagne ${ }^{1}$, Grégoire Huguet $^{1}$, Isabelle Suzanne ${ }^{1}$, Jean-Louis Senon ${ }^{4}$, Gilles Body ${ }^{5}$, Emmanuel Rusch ${ }^{6}$, Guillaume Magnin', Mélanie Voyer ${ }^{4}$, Christian Réveillère ${ }^{3}$, Vincent Camus ${ }^{1,8,9}$

${ }^{1}$ CHRU de Tours, Clinique Psychiatrique Universitaire, 2 boulevard Tonnellé, 37042 Tours Cedex 9, France.

${ }^{2}$ CHRU de Tours, Équipe de Liaison et de Soins en Addictologie, 2 boulevard Tonnellé, 37042 Tours Cedex 9, France.

3 Université François Rabelais de Tours, Département de Psychologie, EA 2114 «Psychologie des Âges de la Vie », 3 rue des Tanneurs BP 4103, 37041 Tours Cedex 1, France.

${ }^{4}$ Centre Hospitalier Henri-Laborit, Service de Psychiatrie, 370 avenue Jacques Cœur, 86021 Poitiers, France.

${ }^{5}$ CHRU de Tours, Service de Gynécologie Obstétrique, 2 boulevard Tonnellé, 37042 Tours Cedex 9, France.

${ }^{6}$ CHRU de Tours, Service d'Information Médicale, Épidémiologie et Économie de la Santé, 2 boulevard Tonnellé, 37042 Tours Cedex 9, France.

${ }^{7}$ CHU de Poitiers, Service de Gynécologie Obstétrique, 2 rue de la Milétrie, 86021 Poitiers, France.

${ }^{8}$ UMR INSERM U930 «Imagerie et Cerveau », 2 boulevard Tonnellé, 37044 Tours Cedex, France.

${ }^{9}$ Université François Rabelais de Tours, 3 rue des Tanneurs BP 4103, 37041 Tours Cedex 1, France.

\section{Corresponding author:}

Paul Brunault, CHRU de Tours, Clinique Psychiatrique Universitaire, 2 boulevard Tonnellé, 37000 Tours, France. e-mail address: paul.brunault@univ-tours.fr

Telephone number: +33-247-478043 ; Fax number: +33-247-478402

Funding: This work was supported by the French National Cancer Institute (grant number INCA05-IS/ESPOIR) with an additional funding from the Cancer League Committees (Ligue contre le Cancer) of the French departments of Indre-et-Loire and Vienne.

Conflict of interest disclosure: The authors declare that they have no conflict of interest.

This is the postprint version (final draft post refereeing) of the following article: " Paul Brunault $^{1,2,3}$, Anne-Laure Champagne ${ }^{1}$, Grégoire Huguet ${ }^{1}$, Isabelle Suzanne ${ }^{1}$, JeanLouis Senon ${ }^{4}$, Gilles Body ${ }^{5}$, Emmanuel Rusch ${ }^{6}$, Guillaume Magnin ${ }^{7}$, Mélanie Voyer ${ }^{4}$, Christian Réveillère ${ }^{3}$, Vincent Camus ${ }^{1,8,9}$ (2016). Major depressive disorder, personality disorders and coping strategies are independent risk factors for lower quality of life in non-metastatic breast cancer patients. Psychooncology: 2016 May;25(5):513-20. doi: 10.1002/pon.3947. Epub 2015 Sep 10 " which has been published in final form at: http://onlinelibrary.wiley.com/doi/10.1002/pon.3947/abstract 


\begin{abstract}
Objective: To identify risk factors for lower quality of life (QOL) in non-metastatic breast cancer patients.

Methods: Our study included 120 patients from the University Hospital Centers of Tours and Poitiers. This cross-sectional study was conducted 7 months after patients' breast cancer diagnosis and assessed QOL (Quality of Life Questionnaire-Core $30=$ QLQ-C30), sociodemographic characteristics, coping strategies (Brief-Cope), physiological and biological variables (e.g., initial tumor severity, types of treatment received), the existence of major depressive disorder (Mini International Neuropsychiatric Interview) and pain severity (QDSA). We assessed personality disorders 3 months after diagnosis (VKP questionnaire). We used multiple linear regression models to determine which factors were associated with physical, emotional and global QOL.
\end{abstract}

Results: Lower physical QOL was associated with major depressive disorder, younger age, a more severe initial tumor stage and the use of the behavioral disengagement coping. Lower emotional QOL was associated with major depressive disorder, the existence of a personality disorder, a more severe pain level, higher use of self-blame and lower use of acceptance coping strategies. Lower global QOL was associated with major depressive disorder, the existence of a personality disorder, a more severe pain level, higher use of self-blame and lower use of positive reframing coping strategies and an absence of hormone therapy.

Conclusions: Lower QOL scores were more strongly associated to variables related to the individual's premorbid psychological characteristics and the manner in which this individual copes with the cancer (e.g., depression, personality and coping) than to cancer-related variables (e.g., treatment types, cancer severity).

Key words: cancer, oncology, quality of life, coping, depression. 


\section{INTRODUCTION}

Breast cancer has become a major public health issue because it is the most common cancer that affects women in terms of both prevalence and incidence [1]. Thanks to better screening and advances in treatment since the $1980 \mathrm{~s}$, there has been a significant reduction in the mortality rate from breast cancer [2], allowing clinicians to focus on improvements in quality of life (QOL) and psychological well-being, rather than solely on life expectancy, in this patient population [3]. The concept of QOL, which refers to the subjective assessment of a patient's health, has become a major outcome measure in medicine (along with mortality and morbidity) because it assesses a patient's subjective view of his/her health and serves as a prognostic factor [4].

Following a diagnosis of breast cancer, an assessment of QOL is an important clinical outcome measure because patients have to face major stressors that are likely to deteriorate their QOL, not only just after diagnosis but also in the long term (e.g., facing a life-threatening illness, painful and impairing treatments, significant role changes, and issues pertaining to body image) $[5,6]$. To design early therapeutic interventions that can improve QOL in this population, a better understanding is needed regarding which factors are associated with QOL.

Several types of factors are considered to be QOL risk factors in non metastatic breast cancer patients, such as individual variables (e.g., younger age, less frequent use of active coping, religious coping and acceptance, personality traits such as high neuroticism) [7-11], and measures of symptoms (e.g., higher pain, higher anxiety and higher depression) $[11,15,16]$. Other studies that focused on biological and physiological variables found mixed results: some authors found that alteration in physical, emotional and social QOL was not associated with tumor severity nor treatment type $[12,13]$, while some others found an association with use of chemotherapy or radiotherapy [14,15]. These studies also demonstrated that QOL could differ depending on the duration of illness $[7,8]$. Finally, social support (that encompasses tangible support, emotional informational support, affectionate support and positive social interaction) was associated with higher QOL and acted as a moderator between depressive symptoms and QOL [17].

Although many studies independently assessed the potential impact of each of these variables, no study assessed the relative impact of these variables on QOL in an integrative model. To our knowledge, no studies assessed whether QOL was more strongly associated with biological variables (i.e., disease severity, treatments) or with variables related to the individual's characteristics prior to the disease and to the manner in which this individual copes with the disease (i.e., measures of symptoms such as depression; individual variables such as coping and personality). In addition, we do not know yet whether depression, personality and coping strategies are three independent risk factors for lower QOL or if their association with QOL is due to other potential confounding variables. Finally, no studies assessed depression and personality using a categorical approach (i.e., major depressive disorder and personality disorder).

To improve our knowledge of the factors that are associated with QOL in multivariate analyses, we proposed and tested a working model that aimed to assess the relative impact of biological and physiological variables (i.e., tumor severity, types of treatment used), individual variables (i.e., age, coping, personality, marital status), and measures of symptoms (i.e., depression, pain) on QOL. This modified model was based on Wilson \& Cleary's QOL theoretical model [18], which is one of the most commonly used and referenced models in the health-related QOL literature [19].

This study aimed to determine which factors were associated with physical, emotional and global QOL in non-metastatic breast cancer patients at the end of their initial treatment phase (7 months after diagnosis). We hypothesized that, even after adjusting for the severity of disease and types of treatment that were received, major depressive disorder, personality disorders and certain coping strategies (i.e., more frequent use of avoidant coping strategies and less frequent use of active coping strategies) were significant and independent risk factors for lower QOL. 


\section{MATERIAL AND METHODS}

\section{Participants and procedure}

The participants in this study were recruited based on protocols from the ESPOIR study (Early Screening for Psycho-Oncological Intervention Research) that aimed to identify early psychological risk factors for psychiatric disorders in breast cancer patients at the end of their treatment phase ( 7 months post diagnosis). Participants were recruited between May 2006 and November 2007 from the Gynecology Department of the Tours and Poitiers University Hospitals, located in France.

Patients were considered eligible for the study if they were being diagnosed with breast cancer for the first time and if no metastasis was detected during their diagnosis. They were also required to understand French. Patients were excluded if they had metastasis, presented with a relapse of breast cancer, had a cancer of another organ in the past, had difficulties with understanding the study or the assessment instruments, or simply refused to participate. The data collection was conducted 7 months after cancer diagnosis by experienced psychologists (except for personality disorders which were assessed 3 months after cancer diagnosis). 141 out of 233 potentially eligible patients participated (response rate $=60.5 \%$ ).

\section{Measured variables}

Individual characteristics (age, personality, coping and marital status)

We assessed the following variables in each patient: age, occupational and marital status (i.e., single or in a relationship).

Personality disorders were assessed using the French version of the VKP questionnaire (Vragenlijst voor Kenmerken van de Persoonlijkheid) [20]. The VKP is a 197-item, self-administered questionnaire based on the International Personality Disorder Examination (IPDE) and evaluates the presence of each of the 10 personality disorders according to the ICD-10 and DSM-IV diagnostic criteria [21].

We assessed coping strategies using the French version of the Brief-COPE scale [22], which is a short version of the COPE inventory [23]. The Brief-COPE assesses 14 coping strategies (two items per coping): active coping, planning, use of instrumental support, use of emotional support, venting, behavioral disengagement, self-distraction, self-blame, positive reframing, humor, denial, acceptance, religion and substance use; a higher score indicating a more frequent occurrence of the particular coping strategy.

\section{Biological and physiological variables (severity of disease, types of treatment received)}

The severity of breast cancer was assessed in each patient using the international Tumor Node Metastasis (TNM) staging system (T0, T1, T2, T3 or T4; N0 or N1) and the detection of hormonal receptors. We also assessed medical data that was related to patient care, including the existence of chemotherapy, tumor excision surgery and/or mastectomy, axillary lymph node dissection, radiotherapy and/or hormone therapy.

\section{Symptom measures: major depressive disorder and pain}

We evaluated the presence of major depressive disorder using the Mini International Neuropsychiatric Interview (MINI) version 5.0.0. The MINI is a semi-structured interview that assesses psychiatric disorders according to the DSM-IV diagnostic criteria. The MINI has been validated by Sheehan et al. [24] and was translated into the French language and validated by Lecrubier et al [25]. The MINI is a reliable and valid instrument to assess major depressive disorder (sensitivity $=96 \%$, specificity $=88 \%$ and kappa coefficient $=0.84[24,25])$.

To assess pain, we utilized the Questionnaire de Douleur Saint Antoine (QDSA) [26], which is an adaptation and French language translation of the McGill Pain Questionnaire [27]. The QDSA is a verbal, multidimensional, self-administered scale that assesses sensorial and affective aspects of pain; higher score indicate a higher pain level. The QDSA has been validated in oncology settings [26]. 
We assessed QOL using the French version of the Quality of Life Questionnaire-Core 30 (QLQ-C30) questionnaire [28], which is an international 30-items questionnaire designed by the European Organization for the Research and Treatment of Cancer (EORTC) to assess cancer-specific QOL [29] and that compose a global QOL scale and five functional scales (i.e., physical, emotional, social, cognitive functioning and ability to work) [29]. Each scale is scored from 0 to 100; higher scores indicate better QOL. In this study, we focused on physical, emotional and global QOL because they are the most frequently studied QLQ-C30 dimensions.

\section{Ethical considerations}

This study was approved by the ethics committee of the University Hospital Center of Tours, France. All procedures have been performed in accordance with the ethical standards described in the 1964 Declaration of Helsinki. All participants provided written informed consent prior to their inclusion in the study.

\section{Statistical analysis}

The R statistical software package version 2.15.2 (R Development Core Team, Vienna, Austria), was used to perform the data analysis of this study [30].

To determine which factors were associated with each QOL dimension (i.e., physical, emotional and global QOL), we used a two-stage approach. First, we used univariate analyses (correlation tests and mean comparisons) to determine which variables were significantly associated with each QOL dimension. Second, we used multivariate analyses (multiple linear regression) to determine which variables were associated with each QOL dimension, after adjusting for potential confounding factors: age, initial tumor stage, use of hormone therapy, pain, presence of major depressive disorder and use of coping strategies. We verified that the basic assumptions for multiple linear regression were met for all of our analyses, especially for the normality of residuals. For each dependent variable, we specified the beta regression coefficient, its standard deviation and the associated $\mathrm{t}$ - and $p$-values. Statistical significance was considered when the $p$-value $\leq 0.05$.

\section{RESULTS}

\section{Population}

A total of 141 patients were initially enrolled in our study shortly after diagnosis. Sixteen of these 141 patients were withdrawn from the study due to metastatic evolution ( 3 patients), withdrawal of consent (6 patients), or loss to follow-up (7 patients). The eligible patient population at the end of the treatment phase consisted of 125 patients; however, 5 participants had missing data from at least one questionnaire. Therefore, our final study population included 120 patients.

\section{Sample characteristics}

Table 1 shows the individual (e.g., age, occupational and marital status, personality, coping), and the biological and physiological variables (e.g., tumor characteristics, types of treatment received) of our population. Mean QOL scores were 83.7 13.4 for physical QOL, 78.5 \pm 23.3 for emotional QOL and $66.7 \pm 18.8$ for global QOL.

\section{Factors associated with physical, emotional and global QOL}

\section{Univariate analyses}

Factors that were associated with each QOL dimension are presented in Table 2. 


\section{Multivariate analyses (Table 3)}

Physical QOL was significantly lower in patients who had a more severe initial tumor stage or major depressive disorder, and in patients who used the behavioral disengagement coping strategy more frequently, but it was not associated with pain, existence of a personality disorder or hormone therapy. These factors explained $13.5 \%$ of the total variation in physical QOL.

Emotional QOL was significantly lower in patients who had higher pain levels, major depressive disorder, or a personality disorder, and in patients who used the self-blame coping strategy more frequently or the acceptance coping strategy less frequently, but it was not associated with age, initial tumor stage or hormone therapy. These factors explained $48.7 \%$ of the total variation in emotional QOL.

Global QOL was significantly lower in patients who had major depressive disorder, in patients who were not prescribed hormone therapy, in patients who used the self-blame coping strategy more frequently, and in patients who used the positive reframing coping strategy less frequently, but it was not associated with age, initial tumor stage, pain level or existence of a personality disorder. These factors explained $26 \%$ of the total variation in global QOL.

\section{DISCUSSION}

In this study, which was conducted in non-metastatic breast cancer patients at the end of their initial treatment phase (7 months after diagnosis), we found that QOL was associated much more to measures of symptoms (i.e., depression) and individual characteristics (i.e., age, personality, coping) than to biological variables (i.e., tumor severity and types of treatment received). We also found that even after adjustment for potential confounding factors, major depressive disorder, personality disorders and coping were three independent and important risk factors for lower QOL.

First, we demonstrated that QOL was more strongly associated to variables related to the individual's characteristics prior to the disease (i.e., age, personality) and to the manner in which this individual copes with the disease (i.e., coping, depression and pain) than to biological or physiological variables related to the severity of the cancer or to its treatment. Our results support the hypothesis that in non-metastatic breast cancer patients, the diagnosis of breast cancer (rather than the severity of this cancer) could reveal specific risk factors for lower QOL, including younger age (i.e., younger patients might experience higher personal and social distress due to their altered body image) [31], higher pain (i.e., these patients might be more susceptible to the fear of cancer recurrence and thus experience lower emotional QOL; higher pain could also be due to higher depression), existence of a psychological vulnerability prior to the diagnosis (i.e., patients with a personality disorder or with depression), and use of some coping strategies after diagnosis. Higher tumor severity could be a less important risk factor associated only with lower physical, but not with emotional nor global QOL $[7,8,12,13]$. In addition, the subjective impact of the treatment rather than the types of treatment used might be risk factors for lower QOL.

Our second main result was that depression, personality disorders and coping were three independent risk factors for lower QOL. The fact that major depressive disorder was the variable associated with the strongest decrease in QOL on all three dimensions (decrease of 38.2 points on emotional QOL, 24.2 points on global QOL and 10.6 points on physical QOL) is in line with previous studies $[15,32,33]$. Depression can have a direct (e.g., via a systematic cognitive bias regarding the treatment of information that leads to a negative self-assessment of health) or indirect (e.g., via a greater difficulty with acquiring new coping strategies that improve QOL) impact on QOL [34].

Existence of a personality disorder was another independent risk factor, but only for lower emotional QOL. To explain the previously demonstrated associations between personality dimensions (i.e., trait anxiety and neuroticism) and physical, emotional and global QOL [9,11], we can assume that the deterioration in global and physical QOL could be due to confounding factors (e.g., depression) while the deterioration in emotional QOL could be directly due to the personality disorder. 
These results suggest that when a patient with a personality disorder reports low physical or global QOL, the personality disorder cannot explain this low QOL and it is important to screen for and treat other risk factors.

Interestingly, the coping strategies associated with lower QOL (i.e., low positive reframing, low acceptance, high self-blame and high behavioural disengagement) were mainly avoidant coping strategies (i.e., coping strategies that lead individuals to activities or mental states that prevent them from directly addressing stressful events) [35]. Although these strategies may be effective in the short term, if the stressor is uncontrollable, it may lead to lower psychological adjustment in the long term [35]. These strategies may also indicate patients who attempt to avoid the experience of grief, which is a natural and normal reaction to losses that are induced by cancer. Alternatively, the association between high QOL and both high positive reframing and high acceptance may also be explained by post-traumatic growth after a diagnosis of cancer (i.e., positive changes that are felt after a difficult life event) [36]. Our results support the idea that QOL is more strongly associated to the manner in which the patient actively copes with the disease (no matter the disease severity) and to the individual characteristics prior to the disease than to the severity of the disease or the types of treatment used.

This study had several limitations, including a small sample size (that did not allow us to study the association between QOL and other less prevalent psychiatric disorders), and the use of a self-administered questionnaire for personality disorders (that may have over-evaluated the prevalence of personality disorders), and the question whether our results are generalizable to other countries or cultures. Another limitation of our study was related to the timing of the assessment (end of the initial treatment phase): long-term studies could potentially identify different risk factors for lower QOL, such as the impact of various types of treatment. Our results are limited to non-metastatic breast cancer patients and to patients with similar levels of symptoms (i.e., pain, depression). Finally, we did not assessed other important risk factors for lower QOL (e.g., social support) nor other QOL dimensions (e.g., social QOL, cognitive functioning or difficulties in ability to work), and we did not use a generic QOL questionnaire to compare our population's QOL scores with the general population.

This study has several practical implications. Our results highlight the need for early screening of all the psychological factors that are associated with lower QOL in breast cancer patients, including major depressive disorder, personality disorders, and certain coping strategies (e.g., low positive reframing, low acceptance, high self-blame, high behavioral disengagement). Better screening and treatment for major depressive disorder is critical given that depressive disorders are highly prevalent in breast cancer patients $[15,38]$ and that these disorders are often underdiagnosed and untreated in this population, despite the existence of effective psychotherapeutic and pharmacologic treatments $[15,39]$. Such interventions may not only improve QOL in these patients but also improve their tolerance and adherence to therapeutic interventions. An early screening program for personality disorders and coping styles may detect which patients are at higher risk for lower psychosocial outcomes. Subsequently, psychotherapeutic interventions may be proposed based on their personality and coping styles (e.g., therapies based on psycho-education with cognitive behavioral interventions such as group therapy, stress management techniques, assertiveness training, problem solving or cognitive restructuration) [40]. In all cases, therapy must be tailored to the individual person, relationship and circumstances that characterize a patient at a particular point in time as they grieve for specific losses [41].

\section{CONCLUSION}

This study demonstrated that in non-metastatic breast cancer, lower physical, emotional and global QOL scores were more strongly associated to variables related to the individual's psychological characteristics prior to the disease and to the manner in which this individual copes with the disease (e.g., major depressive disorder, personality disorders and use of coping strategies) than to biological or physiological variables (e.g., treatment types, cancer severity). Future studies should determine whether therapeutic interventions that are based on these psychological factors could improve QOL in breast cancer patients. 


\section{ACKNOWLEDGMENTS}

We thank Vanessa Davy for translating the initial version of the manuscript into English.

Funding: This work was supported by the French National Cancer Institute (grant number INCA05IS/ESPOIR) with an additional funding from the Cancer League Committees (Ligue contre le Cancer) of the French departments of Indre-et-Loire and Vienne.

Conflict of interest disclosure: The authors declare that they have no conflict of interest.

\section{REFERENCES}

[1] Ferlay J, Shin H, Bray F, Forman D, Mathers C, Parkin D. Estimates of worldwide burden of cancer in 2008: GLOBOCAN 2008. Int J Cancer 2010;127:2893-917.

[2] Rachet B, Maringe C, Nur U, Quaresma M, Shah A, Woods L, et al. Population-based cancer survival trends in England and Wales up to 2007: an assessment of the NHS cancer plan for England. Lancet Oncol 2009;10:351-69.

[3] Montazeri A. Health-related quality of life in breast cancer patients: A bibliographic review of the literature from 1974 to 2007. J Exp Clin Cancer Res 2008;27:32. doi:10.1186/1756-9966-27-32.

[4] Leplège A, Coste J. Mesure de la santé perceptuelle et de la qualité de vie: méthodes et applications. Paris: De Boeck Estem; 2002.

[5] Al-Azri M, Al-Awisi H, Al-Moundhri M. Coping With a Diagnosis of Breast Cancer-Literature Review and Implications for Developing Countries. Breast J 2009;15:615-22. doi:10.1111/j.15244741.2009.00812.x.

[6] Helms RL, O’Hea EL, Corso M. Body image issues in women with breast cancer. Psychol Health Med 2008;13:313-25. doi:10.1080/13548500701405509.

[7] Janz NK, Mujahid M, Lantz PM, Fagerlin A, Salem B, Morrow M, et al. Population-based study of the relationship of treatment and sociodemographics on quality of life for early stage breast cancer. Qual Life Res 2005;14:1467-79. doi:10.1007/s11136-005-0288-6.

[8] Kroenke CH. Functional Impact of Breast Cancer by Age at Diagnosis. J Clin Oncol 2004;22:1849-56. doi:10.1200/JCO.2004.04.173.

[9] Cousson-Gélie F, Sordes-Ader F. Psychologie de la santé et cancers: quels apports et quelles perspectives? Psychol Fr 2012;57:119-29. doi:10.1016/j.psfr.2012.03.001.

[10] Elumelu TN, Asuzu CC, Akin-Odanye EO. Impact of active coping, religion and acceptance on quality of life of patients with breast cancer in the department of radiotherapy, UCH, Ibadan. BMJ Support Palliat Care In Press. doi:10.1136/bmjspcare-2012-000409.

[11] Härtl K, Schennach R, Müller M, Engel J, Reinecker H, Sommer H, et al. Quality of life, anxiety, and oncological factors: a follow-up study of breast cancer patients. Psychosomatics 2010;51:112-23. doi:10.1176/appi.psy.51.2.112.

[12] Burgess C, Cornelius V, Love S, Graham J, Richards M, Ramirez A. Depression and anxiety in women with early breast cancer: five year observational cohort study. Br Med J 2005;330:702-5.

[13] Reich M, Lesur A, Perdrizet-Chevallier C. Depression, quality of life and breast cancer: a review of the literature. Breast Cancer Res Treat 2008;110:9-17.

[14] Härtl K, Engel J, Herschbach P, Reinecker H, Sommer H, Friese K. Personality traits and psychosocial stress: quality of life over 2 years following breast cancer diagnosis and psychological impact factors. Psycho-Oncology 2010;19:160-9. doi:10.1002/pon.1536.

[15] Brunault P, Toledano A, Aguerre C, Suzanne I, Garaud P, Trzepidur-Edom M, et al. [Impact of late treatment-related radiotherapy toxicity, depression, and anxiety on quality of life in long-term breast cancer survivors]. Bull Cancer 2012;99:589-98. doi:10.1684/bdc.2012.1569.

[16] Sundaresan P, Sullivan L, Pendlebury S, Kirby A, Rodger A, Joseph D, et al. Patients' Perceptions of Health-related Quality of Life During and After Adjuvant Radiotherapy for T1N0M0 Breast Cancer. Clin Oncol (R Coll Radiol) 2015;27:9-15. doi:10.1016/j.clon.2014.09.007.

[17] Huang CY, Hsu MC. Social support as a moderator between depressive symptoms and quality of life outcomes of breast cancer survivors. Eur J Oncol Nurs 2013;17:767-774. doi:10.1016/j.ejon.2013.03.011.

[18] Wilson IB, Cleary PD. Linking clinical variables with health-related quality of life. A conceptual model of patient outcomes. JAMA 1995;273:59-65. doi:10.1001/jama.1995.03520250075037.

[19] Bakas T, McLennon SM, Carpenter JS, Buelow JM, Otte JL, Hanna KM, et al. Systematic review of health-related quality of life models. Health Qual Life Outcomes 2012;10:134. doi:10.1186/1477-7525-10134. 
[20] Enfoux A, Courtois R, Duijsens I, Reveillere C, Senon JL, Magnin G, et al. Comorbidity between personality disorders and depressive symptomatology in women: A cross-sectional study of three different transitional life stages: Depression and personality disorders. Personal Ment Health 2013;7:233-41. doi:10.1002/pmh.1228.

[21] Duijsens IJ, Eurelings-Bontekoe EHM, Diekstra RW. The VKP, a self-report instrument for DSM-III-R and ICD-10 personality disorders: construction and psychometric properties. Personal Individ Differ 1996;20:171-82. doi:10.1016/0191-8869(95)00161-1.

[22] Fillion L, Kovacs AH, Gagnon P, Endler NS. Validation of the shortened cope for use with breast cancer patients undergoing radiation therapy. Curr Psychol 2002;21:17-34. doi:10.1007/BF02903157.

[23] Carver CS. You want to measure coping but your protocol' too long: Consider the brief cope. Int J Behav Med 1997;4:92-100. doi:10.1207/s15327558ijbm0401_6.

[24] Sheehan DV, Lecrubier Y, Sheehan KH, Amorim P, Janavs J, Weiller E, et al. The Mini-International Neuropsychiatric Interview (MINI): the development and validation of a structured diagnostic psychiatric interview for DSM-IV and ICD-10. J Clin Psychiatry 1998;59:22-33. doi:10.1016/S0924-9338(97)832968.

[25] Lecrubier Y, Sheehan D, Weiller E, Amorim P, Bonora I, Harnett Sheehan K, et al. The Mini International Neuropsychiatric Interview (MINI). A short diagnostic structured interview: reliability and validity according to the CIDI. Eur Psychiatry 1997;12:224-31. doi:10.1016/S0924-9338(97)83296-8.

[26] Boureau F, Luu M, Doubrère JF. Comparative study of the validity of four French McGill Pain Questionnaire (MPQ) versions. Pain 1992;50:59-65. doi:10.1016/0304-3959(92)90112-O.

[27] Melzack R. The short-form McGill pain questionnaire. Pain 1987;30:191-7. doi:10.1016/03043959(87)91074-8.

[28] Fournier E, Christophe V, Vanlemmens L. Pertinence d'évaluer la qualité de vie des femmes jeunes et de leur partenaire en sénologie. Bull Cancer 2009;96:571-7. doi:10.1684/bdc.2009.0864.

[29] Aaronson NK, Ahmedzai S, Bergman B, Bullinger M, Cull A, Duez NJ, et al. The European Organization for Research and Treatment of Cancer QLQ-C30: A Quality-of-Life Instrument for Use in International Clinical Trials in Oncology. J Natl Cancer Inst 1993;85:365-76. doi:10.1093/jnci/85.5.365.

[30] R Development Core Team. R: A language and environment for statistical computing. 2012.

[31] Bloom J, Petersen D, Kang S. Multi-dimensional quality of life among long-term (5+ years) adult cancer survivors. Psycho-Oncology 2007;16:691-706. doi:10.1002/pon.1208.

[32] Ruo B, Rumsfeld JS, Hlatky MA, Liu H, Browner WS, Whooley MA. Depressive symptoms and healthrelated quality of life: The heart and soul study. JAMA 2003;290:215-21. doi:10.1001/jama.290.2.215.

[33] Ivanauskienè R, Padaiga Ž, Šimoliūnienė R, Smailytė G, Domeikienė A. Well-being of newly diagnosed women with breast cancer: which factors matter more? Support Care Cancer 2014;22:519-26. doi:10.1007/s00520-013-2005-2.

[34] Brunault P, Frammery J, Couet C, Delbachian I, Bourbao-Tournois C, Objois M, et al. Predictors of changes in physical, psychosocial, sexual quality of life, and comfort with food after obesity surgery: a 12month follow-up study. Qual Life Res 2015;24:493-501. doi:10.1007/s11136-014-0775-8.

[35] Bruchon-Schweitzer. Psychologie de la santé: modèles, concepts et méthodes. Dunod, Paris: 2002.

[36] Morrill EF, Brewer NT, O’Neill SC, Lillie SE, Dees EC, Carey LA, et al. The interaction of post-traumatic growth and post-traumatic stress symptoms in predicting depressive symptoms and quality of life. PsychoOncology 2008;17:948-53. doi:10.1002/pon.1313.

[37] Fallowfield L, Ratcliffe D, Jenkins V, Saul J. Psychiatric morbidity and its recognition by doctors in patients with cancer. Br J Cancer 2001;84:1011-5. doi:10.1054/bjoc.2001.1724.

[38] Naaman S, Radwan K, Fergusson D, Johnson S. Status of psychological trials in breast cancer patients: a report of three meta-analyses. Psychiatry 2009;72:50-69. doi:10.1521/psyc.2009.72.1.50.

[39] Dolbeault S, Brédart A, Cayrou S. Groupes psycho-éducationnels à destination de patients atteints de cancer: quels fondements, quels objectifs, quel format en pratique ? Psycho-Oncol 2010;4:180-9. doi:10.1007/s11839-010-0266-2.

[40] Hall C. Beyond Kubler-Ross: recent developments in our understanding of grief and bereavement. 2011. http://search.informit.com.au/documentSummary;dn=201201303;res=IELAPA (accessed October 13, 2014). 


\section{TABLES}

Table 1. Individual characteristics, biological and physiological variables, and symptom measures of the study population $(n=120)$.

Individual characteristics

$\operatorname{Mean}( \pm$ SD)

Number of patients $(\%)$

Age at diagnosis (years)

$56.4( \pm 10.8)$

Marital status (single)

$37(30.8 \%)$

Occupational status (employed)

$66(55.4 \%)$

Existence of a personality disorder (VKP)

$40(33.3 \%)$

Cluster A personality disorder

$28(23.3 \%)$

Cluster B personality disorder

$9(7.5 \%)$

Cluster $\mathrm{C}$ personality disorder

$22(18.3 \%)$

\section{Biological and physiological variables}

Initial tumor characteristics (TNM)

$\mathrm{T}$ (tumor)

$\mathrm{T}=0$

$16(13.3 \%)$

$\mathrm{T}=1$

$56(46.7 \%)$

$\mathrm{T}=2$

$37(30.8 \%)$

$\mathrm{T}=3$

$5(4.2 \%)$

$\mathrm{T}=4$

$3(2.5 \%)$

$\mathrm{N}$ (existence of nodes)

$17(14.2 \%)$

Hormonal receptors (presence)

$98(81.7 \%)$

Types of treatment received

Mastectomy

Tumor excision

$44(36.7 \%)^{1}$

$90(75 \%)$

Chemotherapy

$69(57.5 \%)$

Radiotherapy

$108(90 \%)$

Hormone therapy

$54(45 \%)$

\section{Symptom measures}

Major depressive disorder (MINI)

$13(10.8 \%)$

Pain (total QDSA score)

$6.7( \pm 6.2)$

Legend:

${ }^{1}$ Some patients received more than one type of surgery. 
Table 2. Factors associated with physical, emotional and global QOL in univariate analyses.

\begin{tabular}{|c|c|c|c|c|c|c|}
\hline \multirow{3}{*}{ Individual characteristics } & \multicolumn{2}{|c|}{ Physical QOL } & \multicolumn{2}{|c|}{ Emotional QOL } & \multicolumn{2}{|c|}{ Global QOL } \\
\hline & \multirow[t]{2}{*}{ Test } & \multirow[t]{2}{*}{$p$} & \multirow[t]{2}{*}{ Test } & \multirow[t]{2}{*}{$p$} & \multirow[t]{2}{*}{ Test } & \multirow[t]{2}{*}{$p$} \\
\hline & & & & & & \\
\hline Age at diagnosis & $\mathrm{r}=-0.13$ & 0.16 & $\mathrm{r}=0.09$ & 0.35 & $\mathrm{r}=0.14$ & 0.14 \\
\hline Marital status (single) & $\mathrm{t}=-1.12$ & 0.26 & $\mathrm{t}=0.10$ & 0.92 & $\mathrm{t}=0.50$ & 0.62 \\
\hline Occupational status & $\mathrm{F}=1.23$ & 0.29 & $\mathrm{~F}=1.56$ & 0.15 & $\mathrm{~F}=1.62$ & 0.14 \\
\hline \multicolumn{7}{|l|}{ Personality disorder (PD) } \\
\hline Existence of a PD & $\mathrm{t}=-\mathbf{2 . 3 6}$ & $<0.001$ & $\mathrm{t}=\mathbf{- 5 . 1 8}$ & $<0.001$ & $\mathrm{t}=-1.67$ & 0.10 \\
\hline Cluster A PD & $\mathrm{t}=\mathbf{- 3 . 3 0}$ & $<0.001$ & $\mathrm{t}=\mathbf{- 5 . 9 3}$ & $<0.001$ & $\mathrm{t}=-\mathbf{2 . 3 7}$ & 0.02 \\
\hline Cluster B PD & $t=-3.03$ & $<0.01$ & $t=-4.99$ & $<0.001$ & $t=-2.70$ & $<0.01$ \\
\hline Cluster C PD & $\mathrm{t}=-2.41$ & 0.02 & $\mathrm{t}=-4.26$ & $<0.001$ & $\mathrm{t}=-2.04$ & $<0.05$ \\
\hline \multicolumn{7}{|l|}{ Coping } \\
\hline Active coping & $\mathrm{r}=-0.04$ & 0.70 & $\mathrm{r}=-0.07$ & 0.44 & $\mathrm{r}=-0.08$ & 0.38 \\
\hline Planning & $\mathrm{r}=0.08$ & 0.40 & $\mathrm{r}=-0.07$ & 0.48 & $\mathrm{r}=-0.03$ & 0.74 \\
\hline $\begin{array}{l}\text { Searching for social/emotional } \\
\text { support }\end{array}$ & $\mathrm{r}=0.01$ & 0.94 & $\mathrm{r}=-\mathbf{0 . 1 9}$ & 0.04 & $\mathbf{r}=-\mathbf{0 . 1 8}$ & 0.05 \\
\hline Venting & $\mathrm{r}=-0.03$ & 0.73 & $\mathrm{r}=-\mathbf{0 . 2 1}$ & 0.02 & $\mathrm{r}=-0.15$ & 0.11 \\
\hline Behavioral disengagement & $r=-0.30$ & $<0.001$ & $\mathrm{r}=-\mathbf{0 . 3 2}$ & $<0.001$ & $r=-0.22$ & 0.02 \\
\hline Distraction & $\mathrm{r}=-0.10$ & 0.30 & $\mathrm{r}=-0.13$ & 0.15 & $\mathrm{r}=-0.15$ & 0.11 \\
\hline Self-blame & $r=-0.19$ & 0.04 & $\mathrm{r}=-\mathbf{0 . 3 9}$ & $<0.001$ & $\mathrm{r}=-\mathbf{0 . 4 0}$ & $<0.001$ \\
\hline Positive reframing & $\mathrm{r}=0.15$ & 0.09 & $\mathrm{r}=\mathbf{0 . 2 0}$ & 0.03 & $\mathrm{r}=0.24$ & $<0.01$ \\
\hline Humor & $\mathrm{r}=-0.02$ & 0.79 & $\mathrm{r}=0.21$ & 0.02 & $\mathrm{r}=0.24$ & $<0.01$ \\
\hline Denial & $\mathrm{r}=-0.15$ & 0.12 & $r=-\mathbf{0 . 4 0}$ & $<0.001$ & $\mathrm{r}=-0.17$ & 0.06 \\
\hline Acceptance & $\mathrm{r}=0.17$ & 0.06 & $\mathrm{r}=\mathbf{0 . 5 3}$ & $<0.001$ & $\mathrm{r}=\mathbf{0 . 3 3}$ & $<0.001$ \\
\hline Religion & $\mathrm{r}=-0.02$ & 0.80 & $\mathrm{r}=-0.17$ & 0.07 & $\mathrm{r}=-0.04$ & 0.69 \\
\hline Substance use & $r=-0.21$ & 0.02 & $\mathrm{r}=-0.11$ & 0.23 & $\mathrm{r}=-0.16$ & 0.08 \\
\hline \multicolumn{7}{|l|}{ Biological and physiological variables } \\
\hline \multicolumn{7}{|l|}{ Initial tumor characteristics } \\
\hline $\mathrm{T}$ & $\mathrm{t}=-1.50$ & 0.14 & $\mathrm{t}=-0.49$ & 0.63 & $\mathrm{t}=-0.78$ & 0.43 \\
\hline $\mathrm{N}$ & $\mathrm{t}=-0.89$ & 0.38 & $\mathrm{t}=0.16$ & 0.87 & $\mathrm{t}=-0.53$ & 0.60 \\
\hline Presence of hormonal receptors & $\mathrm{t}=-0.35$ & 0.73 & $\mathrm{t}=0.75$ & 0.46 & $\mathrm{t}=-0.23$ & 0.82 \\
\hline \multicolumn{7}{|l|}{ Types of treatment received } \\
\hline Mastectomy & $\mathrm{t}=-1.25$ & 0.21 & $\mathrm{t}=-0.40$ & 0.69 & $\mathrm{t}=-0.03$ & 0.98 \\
\hline Tumor excision & $\mathrm{t}=0.79$ & 0.43 & $\mathrm{t}=0.13$ & 0.91 & $\mathrm{t}=0.12$ & 0.91 \\
\hline Chemotherapy after surgery & $\mathrm{t}=-0.12$ & 0.91 & $\mathrm{t}=0.34$ & 0.74 & $\mathrm{t}=-1.19$ & 0.24 \\
\hline Radiotherapy & $\mathrm{t}=1.46$ & 0.15 & $\mathrm{t}=1.02$ & 0.31 & $\mathrm{t}=0.15$ & 0.88 \\
\hline Hormone therapy & $\mathrm{t}=0.30$ & 0.76 & $\mathrm{t}=0.97$ & 0.33 & $\mathrm{t}=\mathbf{2 . 7 2}$ & $<0.01$ \\
\hline \multicolumn{7}{|l|}{ Symptom measures } \\
\hline Major depressive disorder (MINI) & $\mathrm{t}=-\mathbf{3 . 2 2}$ & $<0.01$ & $\mathrm{t}=\mathbf{= 8 . 8 1}$ & $<0.001$ & $\mathrm{t}=-\mathbf{5 . 2 0}$ & $<0.001$ \\
\hline Pain (total QDSA score) & $\mathrm{r}=\mathbf{- 0 . 2 5}$ & $<0.01$ & $r=-\mathbf{0 . 4 0}$ & $<0.001$ & $\mathbf{r}=\mathbf{- 0 . 3 0}$ & $<\mathbf{0 . 0 0 1}$ \\
\hline
\end{tabular}


Table 3. Factors associated with physical, emotional and global QOL in multiple linear regression.

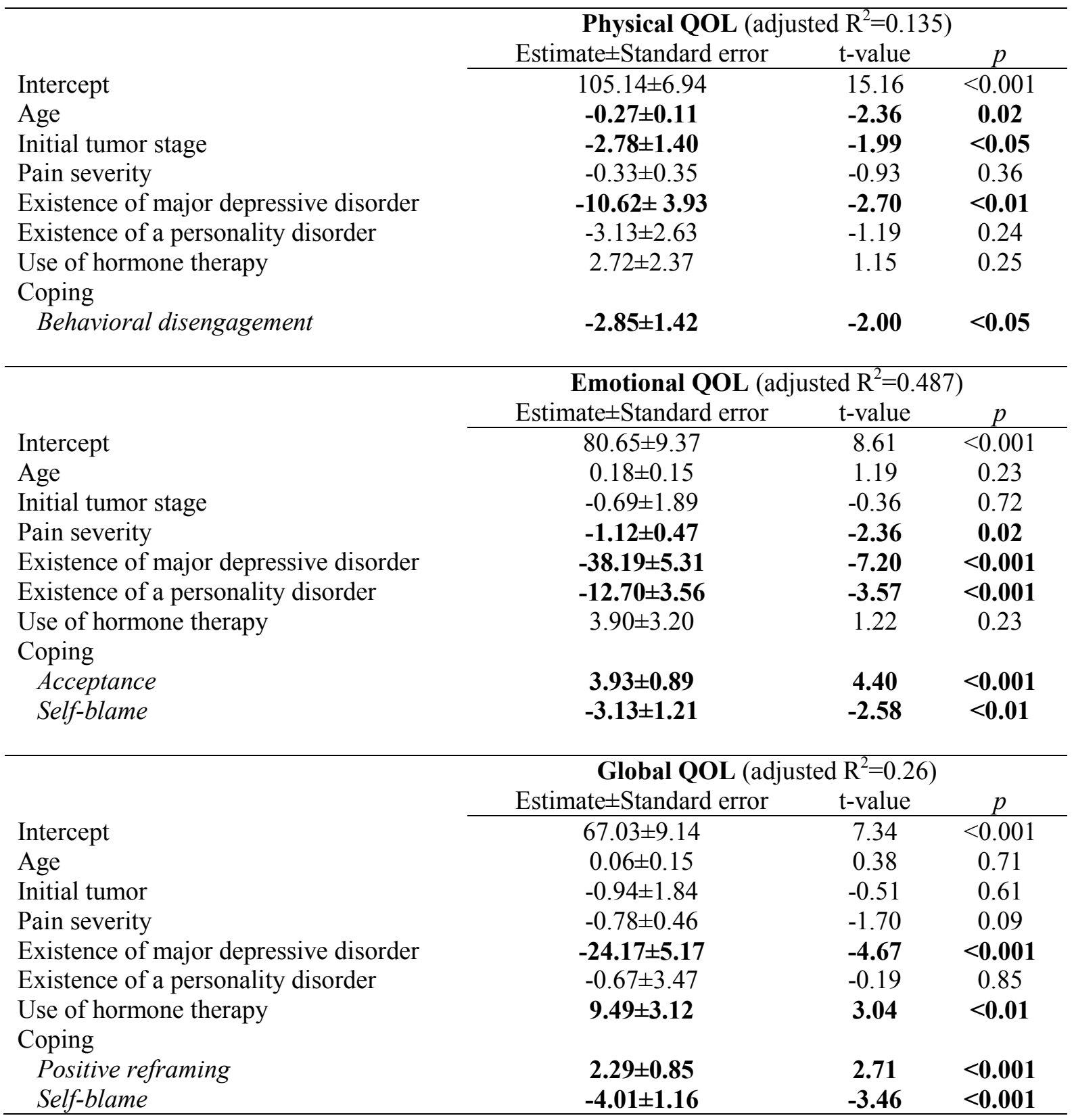

Legends:

An estimate of -38.19 for the "existence of major depressive disorder" variable indicates that this variable is associated with a significant decrease of 38.19 points in the emotional QOL score, on a 0 to 100 scale.

Factors significantly associated with QOL scores are indicated in bold. 